\title{
Current practices in endoscopic submucosal dissection for colorectal neoplasms: a survey of indications among Korean endoscopists
}

\author{
Tae Jun Kim, Eun Ran Kim, Sung Noh Hong, Young-Ho Kim, Dong Kyung Chang \\ Department of Medicine, Samsung Medical Center, Sungkyunkwan University School of Medicine, Seoul, Korea
}

\begin{abstract}
Background/Aims: The indications for colorectal endoscopic submucosal dissection (ESD) vary in clinical practice. To establish colorectal ESD as a standard treatment, standard indications are essential. For establishing standard indications for colorectal ESD, we surveyed the preferences and criteria of endoscopists for colorectal ESD in their practices. Methods: A multiple-choice questionnaire was sent to 27 members of the Korean Society of Gastrointestinal Endoscopy/ESD group. The indications of endoscopists for selecting ESD as a treatment for colorectal tumors $\geq 2 \mathrm{~cm}$ in diameter were surveyed. Results: On the basis of the preprocedural assessment of histology, adenoma with high-grade dysplasia, mucosal cancer, and shallow submucosa invasive cancer were included in the indication for ESD. Based on gross morphology, laterally spreading tumor (LST) granular nodular mixed type, LST-nongranular (LST-NG) flat elevated type, and LST-NG pseudodepressed type were included. On the basis of the pit pattern by Kudo classification, types III, IV, and V-I were included. Based on the narrow band imaging pattern by Sano classification, types II and III-a were included. Other lesions, such as sporadic localized tumors in chronic inflammation and local residual early carcinoma after endoscopic resection, were also included in the indication for ESD. Conclusions: The indications of Korean endoscopists for colorectal ESD are broader than those in recent guidelines, and tend to include more benign-looking tumors. To find the appropriate indications for colorectal ESD, systematic data collection and analysis are required to reach a consensus in a timely manner. (Intest Res 2017;15:228-235)
\end{abstract}

Key Words: Endoscopic mucosal resection; Indication; Colorectal neoplasms

\section{INTRODUCTION}

Endoscopic submucosal dissection (ESD) is an innovative endoscopic technique that allows for en bloc resection of superficial gastrointestinal tumors regardless of their size. This allows for the precise histopathological assessment of specimen margins and reduces the risk of recurrence compared with endoscopic piecemeal mucosal resection (EPMR) on

Received January 7, 2016. Revised March 13, 2016.

Accepted March 28, 2016. Published online March 21, 2017

Correspondence to Dong Kyung Chang, Division of Gastroenterology,

Department of Medicine, Samsung Medical Center, Sungkyunkwan

University School of Medicine, 81 Irwon-ro, Gangnam-gu, Seoul 06351,

Korea. Tel: +82-2-3410-3409, Fax: +82-2-3410-6983, E-mail: dkchang@

skku.edu

Financial support: None. Conflict of interest: None. long-term follow-up..$^{1-3}$ In Korea and Japan, ESD is routinely performed in the endoscopic treatment of superficial gastric neoplasias, ${ }^{4-6}$ and is becoming the standard treatment for colorectal neoplasias such as early colorectal cancer or benign colorectal tumors $\geq 2 \mathrm{~cm}$ for which en bloc resection with conventional endoscopic mucosal resection (EMR) is difficult. In a comparative study of ESD versus EMR for colorectal tumors $\geq 2 \mathrm{~cm}^{7-9}$ there was a $2 \%$ recurrence rate in the ESD group versus $14 \%$ in the EMR group, which also required additional EMR.

However, there are some limitations in performing colorectal ESD, as colorectal ESD is technically more difficult than conventional EMR and has a high risk of complications such as perforation and bleeding. Furthermore, serious peritonitis can develop from colonic perforation and as a

\footnotetext{
(c) Copyright 2017. Korean Association for the Study of Intestinal Diseases. All rights reserved.

This is an Open Access article distributed under the terms of the Creative Commons Attribution Non-Commercial License (http://creativecommons.org/licenses/by-nc/4.0)

which permits unrestricted non-commercial use, distribution, and reproduction in any medium, provided the original work is properly cited.
} 
result of secondary contamination by colonic bacteria and feces. ${ }^{5,710}$ Therefore, accurate preprocedural diagnosis of the lesion and selection of the appropriate treatment from a precise diagnosis are important. According to a recent guideline, ${ }^{11}$ when endoscopic treatment is performed for a large colorectal tumor, en bloc resection such as ESD is the principal approach. However, piecemeal resection is also acceptable except in cases of definitive submucosal invasion. In addition, depending on the skill of the endoscopist or the current practice in the hospital, there can be variations in the selection of the treatment method.

Colorectal ESD was introduced in Korea in 2003 and is now being routinely performed at major teaching hospitals. The outcomes of colorectal ESD in Korea are comparable to those in Japan. ${ }^{4,12}$ However, the indications for colorectal ESD are still controversial. To establish colorectal ESD as a standard treatment, consistent preprocedural diagnosis of the colorectal lesion and selection of appropriate treatment options are required. In order to establish a standard indication for colorectal ESD, we sought to investigate the preferred criteria of ESD experts for colorectal ESD in their practice.

\section{METHODS}

\section{Study Subjects and Methods}

Multiple-choice questionnaires were sent to 27 expert members of the Korean Society of Gastrointestinal Endos-

Table 1. Evaluation Factors for the Selection of Treatment Method

\begin{tabular}{|c|c|}
\hline Factor & Type of tumor \\
\hline \multirow[t]{5}{*}{ Preprocedural assessment of histology } & Adenoma, low-grade dysplasia \\
\hline & Adenoma, high-grade dysplasia \\
\hline & Mucosal cancer \\
\hline & SM invading cancer, shallow \\
\hline & SM invading cancer, massive looking \\
\hline \multirow[t]{4}{*}{ Endoscopic morphology } & LST-G homogeneous type \\
\hline & LST-G nodular mixed type \\
\hline & LST-NG flat elevated type \\
\hline & LST-NG pseudo-depressed type \\
\hline \multirow[t]{2}{*}{ Presence of depression or ulcer } & Any tumor with Ilc area \\
\hline & Any tumor with ulcer \\
\hline \multirow[t]{4}{*}{ Pit pattern (Kudo classification) } & Type II \\
\hline & Type III or IV \\
\hline & Type V-I (irregular) \\
\hline & Type V-N (nonstructural) \\
\hline \multirow[t]{4}{*}{ NBI pattern (Sano-Emura classification) } & Type I \\
\hline & Type II (thick capillary pattern) \\
\hline & Type III-a (nonuniform irregular capillary pattern) \\
\hline & Type III-b (avascular pattern) \\
\hline \multirow[t]{2}{*}{ Nonlifting sign (benign fibrosis looking) } & Partially nonlifted lesions with benign fibrosis \\
\hline & Severely nonlifted lesions with benign fibrosis \\
\hline \multirow[t]{2}{*}{ Nonlifting sign (shallow SM invasion is suspected) } & Shallow SM-invasive cancer suspected, and partially nonlifted \\
\hline & Shallow SM-invasive cancer suspected, and severely nonlifted \\
\hline \multirow[t]{2}{*}{ Nonlifting sign (massive SM invasion is suspected) } & Massive SM-invasive cancer suspected, and partially nonlifted \\
\hline & Massive SM-invasive cancer suspected, and severely nonlifted \\
\hline \multirow[t]{2}{*}{ Special situation } & Sporadic localized tumors in chronic inflammation \\
\hline & Local residual early cancer after endoscopic resection \\
\hline
\end{tabular}

SM, submucosal; LST-G, laterally spreading tumor granular; LST-NG, laterally spreading tumor nongranular; NBI, narrow band imaging. 
copy/ESD group and the Korean Association for the Study of Intestinal Disease. The potential participants were gastroenterologists experienced in colorectal ESD at tertiary referral centers. In June 2013, they were asked to complete the questionnaire via e-mail. Of the 27 gastroenterologists, 18 completed the survey (response rate, 66.7\%). Among these, nine had performed colorectal ESD in $>100$ cases, and the remaining had performed the procedure in $<100$ cases.

The survey consisted of 33 questions that explored the criteria for selecting a treatment method for colorectal tumors (Table 1). In this study, we defined shallow submucosal invasion as $<1,000 \mu \mathrm{m}$ and massive submucosal invasion as $>1,000 \mu \mathrm{m}$. In selecting a therapeutic approach, assessment of clinicopathologic characteristics of the tumor is important, and several factors or situations must be taken into consideration. These include (1) preprocedural histology, (2) endoscopic gross morphology of the tumor, (3) presence of a depression or ulcer on the surface of the tumor, (4) the pit pattern of the tumor (by Kudo classification) ${ }_{1}^{13}(5)$ narrow band imaging (NBI) pattern of the tumor (by Sano-Emura classification), ${ }^{14}$ (6) lifting or nonlifting sign of the tumor, (7) sporadic localized tumor in chronic inflammation, and (8) local residual early cancer after endoscopic resection. For each situation, the survey asked, "which method was the optimal treatment option?" (1) EPMR (or preferring EPMR), (2) either EPMR or ESD, (3) ESD (or preferring ESD), (4) either ESD or surgery, and (5) surgery (or preferring surgery). The 18 participants decided on their most appropriate treatment method in five options. The survey was completed anony- mously. Moreover, there were no costs or patient contact involved, and the survey carried no risks. As we did not use patient information, Institutional Review Board approval was not required.

\section{Statistical Analysis}

As the numbers were not large enough for a statistical comparison, we performed a descriptive analysis.

\section{RESULTS}

The results consisted of 33 questions and answers that explored the indications of endoscopists for selecting a treatment method in colorectal tumors $\geq 2 \mathrm{~cm}$ (Figs 1-6). The colorectal ESD indication for colorectal tumors $<2 \mathrm{~cm}$ is also presented in Supplementary Fig. 1.

\section{Decision Making Based on the Preprocedural Assessment of Histology for the Treatment of Tumors $\geq \mathbf{2} \mathbf{c m}$ in Diameter}

Fig. 1 presents the results of questions that addressed the decision of endoscopists concerning the treatment method based on the preprocedural histologic assessment of the tumor. When the preprocedural histologic diagnosis was lowgrade adenoma, $41.7 \%$ of endoscopists selected EPMR or ESD, and another $30.6 \%$ selected EPMR for the treatment of the tumor. For high-grade adenoma, 58.3\% of endoscopists
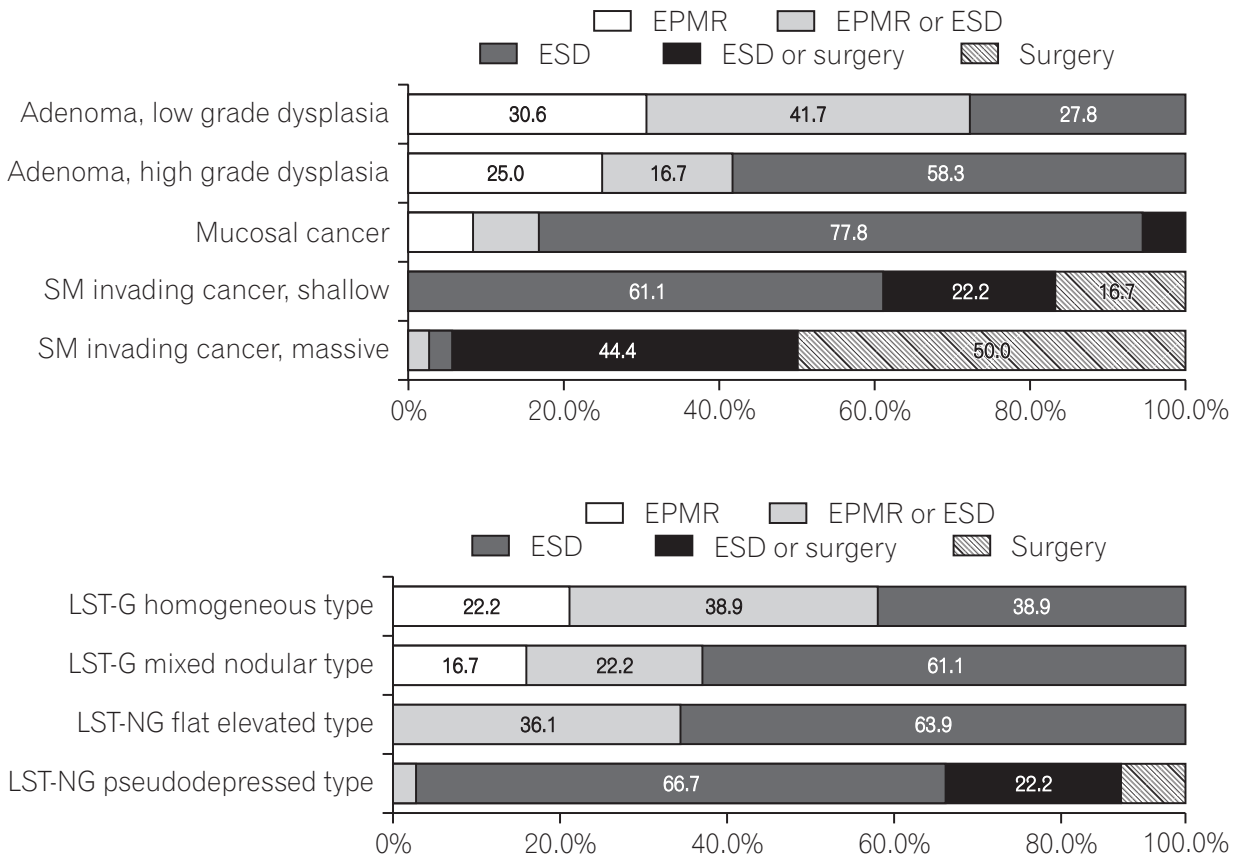

Fig. 1. Approaches of endoscopists to the treatment of tumors $\geq 2 \mathrm{~cm}$ in diameter: preprocedural assessment of histology. $\mathrm{SM}_{\text {, }}$ submucosa; EPMR, endoscopic piecemeal mucosal resection; ESD, endoscopic submucosal dissection.

Fig. 2. Approaches of endoscopists to the treatment of tumors $\geq 2 \mathrm{~cm}$ in diameter: preprocedural assessment of morphology. LST-G, laterally spreading tumor granular; LST-NG, LST-nongranular; EPMR, endoscopic piecemeal mucosal resection; ESD, endoscopic submucosal dissection. 

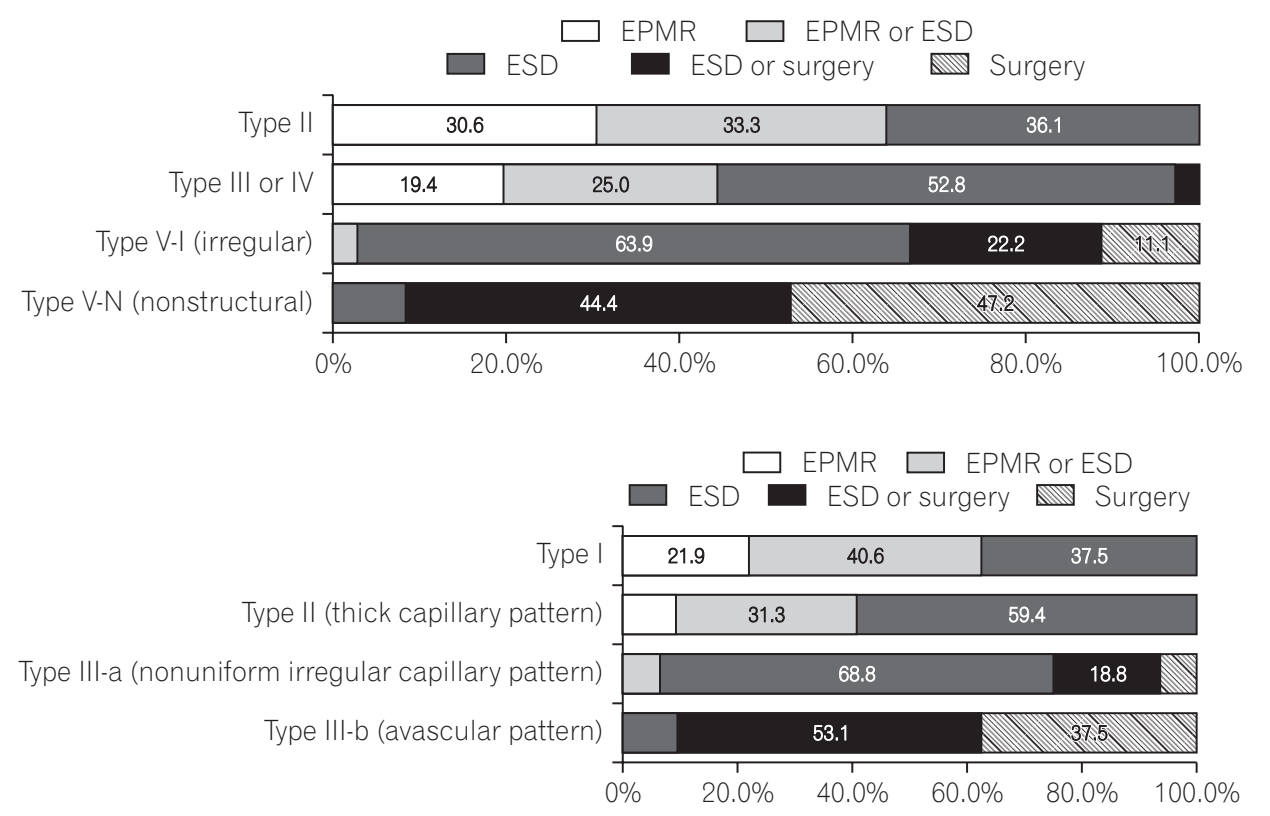

Fig. 3. Approaches of endoscopists to the treatment of tumors $\geq 2 \mathrm{~cm}$ in diameter: preprocedural assessment of pit pattern. EPMR, endoscopic piecemeal mucosal resection; ESD, endoscopic submucosal dissection.

Fig. 4. Approaches of endoscopists to the treatment of tumors $\geq 2 \mathrm{~cm}$ in diameter: preprocedural assessment of narrow band imaging pattern. EPMR, endoscopic piecemeal mucosal resection; ESD, endoscopic submucosal dissection.

selected ESD and another 25.0\% selected EPMR for the treatment of the tumor. For mucosal cancer, $77.8 \%$ of endoscopists selected ESD. For shallow submucosa invasive cancer, $61.1 \%$ of endoscopists selected ESD and another $22.2 \%$ selected surgery or ESD for the treatment of the tumor.

\section{Decision Making Based on Endoscopic Gross Morphology for the Treatment of Laterally Spreading Tumors $\geq 2 \mathrm{~cm}$ in Diameter}

Fig. 2 presents the results of questions that addressed the decision of endoscopists about the treatment method based on the endoscopic gross morphology type of laterally spreading tumors (LSTs). When the gross morphology of the tumor is LST-granular (LST-G) homogeneous type, $38.9 \%$ of endoscopists selected EPMR or ESD. For LST-G nodular mixed type, $61.1 \%$ of endoscopists selected ESD and another $22.2 \%$ selected EPMR. For LST-nongranular (LST-NG) flat elevated type, $63.9 \%$ of endoscopists selected ESD and another $36.1 \%$ selected EPMR or ESD. For LST-NG pseudodepressed type, $66.7 \%$ of the endoscopists selected ESD and another $22.2 \%$ selected surgery or ESD.

\section{Decision Making Based on the Pit Pattern (Kudo Classification) for the Treatment of Tumors $\geq 2 \mathrm{~cm}$ in Diameter}

Fig. 3 presents the results from questions that addressed the decision of endoscopists about the treatment method based on the pit pattern of the tumor. When the tumor showed a type II pit pattern, $36.1 \%$ of endoscopists selected ESD and another 33.3\% selected EPMR or ESD for the treatment of the tumor. For tumors with type III or IV pit pattern, $52.8 \%$ of endoscopists selected ESD and another $25.0 \%$ selected EPMR or ESD. For tumors with type V-I (irregular) pit pattern, $63.9 \%$ of endoscopists selected ESD and another $22.2 \%$ selected surgery or ESD. For tumors showing type V-N (nonstructural) pit pattern, $47.2 \%$ of endoscopists selected surgery and another $44.4 \%$ selected surgery or ESD for the treatment of the tumor.

\section{Decision Making Based on the NBI Pattern (Sano- Emura Classification) for the Treatment of Tumors $\geq 2 \mathrm{~cm}$ in Diameter}

Fig. 4 presents the results from the decision of endoscopists about the treatment method based on the NBI pattern of the tumor. When the tumor showed type I NBI pattern, $40.6 \%$ of endoscopists selected EPMR or ESD and another $37.5 \%$ selected ESD. For tumors with type II (thick capillary) NBI pattern, $59.4 \%$ of endoscopists selected ESD and another 31.3\% selected EPMR or ESD. For tumors showing type III-a (nonuniform irregular capillary) NBI pattern, $68.8 \%$ of endoscopists selected ESD. For tumors showing type IIIb (avascular) NBI pattern, most of the endoscopists (53.1\%) selected surgery or ESD and another $37.5 \%$ selected surgery for the treatment of the tumor. 


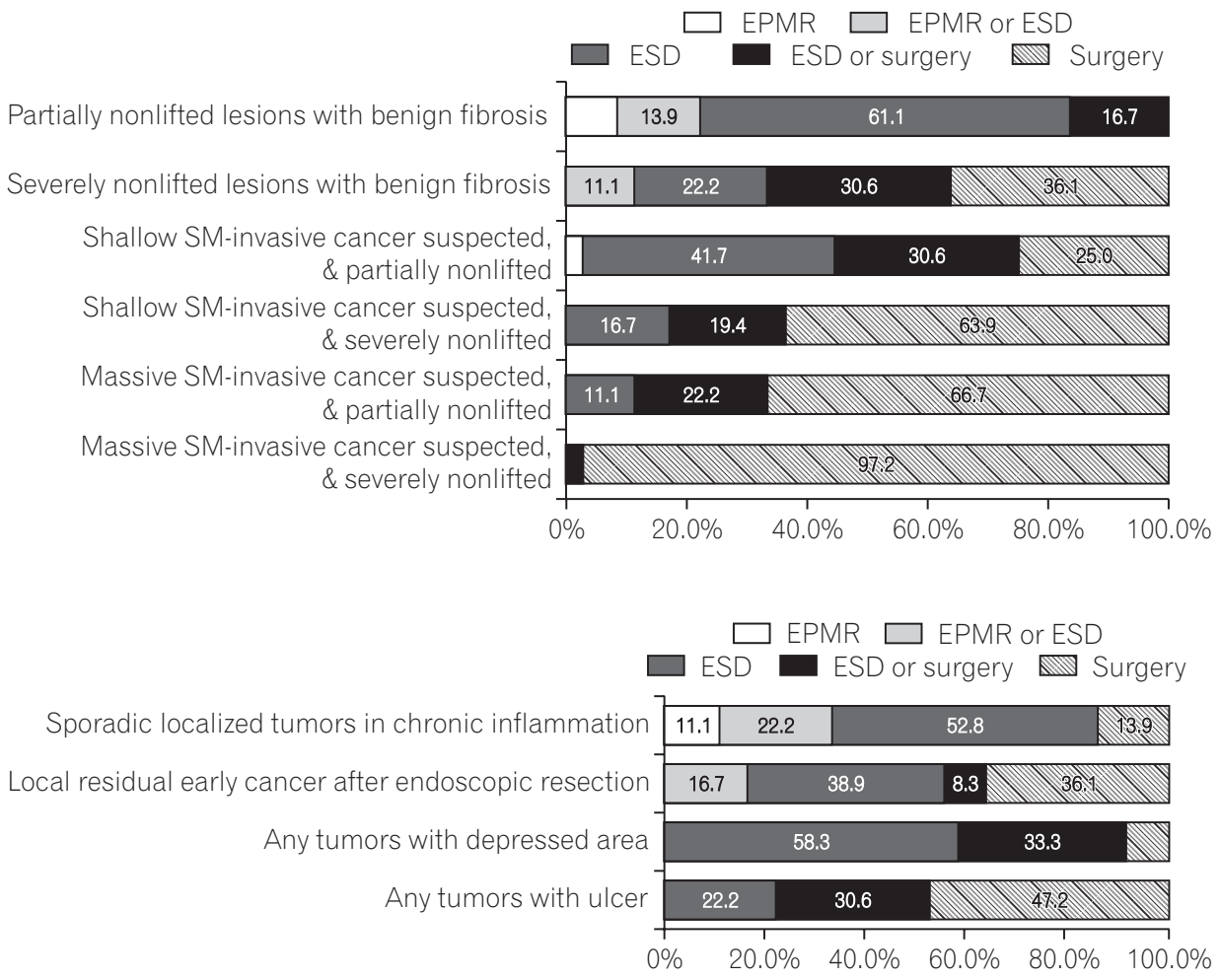

Fig. 5. Approaches of endoscopists to the treatment of tumors $\geq 2 \mathrm{~cm}$ in diameter: preprocedural assessment of the nonlifting sign. SM, submucosa; EPMR, endoscopic piecemeal mucosal resection; ESD, endoscopic submucosal dissection.

Fig. 6. Approaches of endoscopists to the treatment of tumors $\geq 2 \mathrm{~cm}$ in diameter: preprocedural assessment of special situations. EPMR, endoscopic piecemeal mucosal resection; ESD, endoscopic submucosal dissection.

\section{Decision Making Based on the Nonlifting Sign for the Treatment of Tumors $\geq 2 \mathrm{~cm}$ in Diameter}

Fig. 5 presents the results from the decision of endoscopists about the treatment method based on the nonlifting sign of the tumor. When the tumor showed a partially nonlifting sign with benign fibrosis, $61.1 \%$ of endoscopists selected ESD. For tumors showing severe nonlifting sign with benign fibrosis, $36.1 \%$ of endoscopists selected surgery and another $30.6 \%$ selected ESD or surgery. For tumors that showed a partially nonlifting sign and suspected shallow submucosa-invasive cancer, $41.7 \%$ of endoscopists selected ESD and another $30.6 \%$ selected ESD or surgery. For tumors that showed severe nonlifting sign and suspected shallow submucosa-invasive cancer, $63.9 \%$ of endoscopists selected surgery and another $22.2 \%$ selected ESD or surgery for the treatment of the tumor.

\section{Decision Making Based on the Presence of Depression or Ulcer on the Surface of Tumors $\geq 2 \mathrm{~cm}$ in Diameter}

Fig. 6 presents the results from questions that addressed the decisions of endoscopists about the treatment method based on the presence of a depression or ulcer on the surface of the tumor. For any tumor with a depressed area, $58.3 \%$ selected ESD and another $33.3 \%$ selected surgery or
ESD. For any tumor with an ulcer, $47.2 \%$ of endoscopists selected surgery and another $30.6 \%$ selected ESD or surgery.

\section{Decision Making in Special Situations Such as Sporadic Localized Tumors in Chronic Inflammation and Local Residual Early Cancer after Endoscopic Resection}

Fig. 6 presents the results from questions that addressed the decision of endoscopists about the treatment method in special situations. For sporadic localized tumors in chronic inflammation, 52.8\% of endoscopists selected ESD and another 22.2\% selected EPMR or ESD. For local residual early cancer after endoscopic resection, $38.9 \%$ of endoscopists selected ESD and another 36.1\% selected surgery for the treatment of the tumor.

\section{Preference for Evaluation Tools for Depth of Tumor Invasion}

Table 2 presents the results from questions that addressed the preference of endoscopists about the tool for evaluating the depth of tumor invasion. Korean endoscopists rarely $(<10 \%)$ or sometimes $(10 \%-50 \%)$ use EUS for decisions about colorectal ESD. NBI is used sometimes $(10 \%-50 \%)$ in selecting ESD for colorectal neoplasms. Magnification endoscopy is used rarely $(<10 \%)$ in selecting ESD for colorectal 
Table 2. Evaluation Methods to Determine Whether Endoscopic Submucosal Dissection Is Indicated

\begin{tabular}{|c|c|c|}
\hline Question & Answer (\%) & \\
\hline \multirow{5}{*}{$\begin{array}{l}\text { Is the use of magnification endoscopy essential to determine whether } \\
\text { ESD is indicated? }\end{array}$} & 1. No (HD level endoscopy is enough) & 27.3 \\
\hline & 2. Rarely $(<10 \%)$ & 63.6 \\
\hline & 3. Sometimes (10\%-50\%) & 0 \\
\hline & 4. Usually (>50\%) & 9.1 \\
\hline & 5. Almost always (>90\%) & 0 \\
\hline \multirow[t]{5}{*}{ Is the use of NBI essential to determine whether ESD is indicated? } & 1. No (HD level endoscopy is enough) & 15.4 \\
\hline & 2. Rarely $(<10 \%)$ & 23.1 \\
\hline & 3. Sometimes (10\%-50\%) & 30.8 \\
\hline & 4. Usually (>50\%) & 23.1 \\
\hline & 5. Almost always (>90\%) & 7.7 \\
\hline \multirow[t]{5}{*}{ Is the use of EUS essential to determine whether ESD is indicated? } & 1. No (HD level endoscopy is enough) & 23.1 \\
\hline & 2. Rarely $(<10 \%)$ & 38.5 \\
\hline & 3. Sometimes $(10 \%-50 \%)$ & 38.5 \\
\hline & 4. Usually (>50\%) & 0 \\
\hline & 5. Almost always (>90\%) & 0 \\
\hline \multirow[t]{2}{*}{ Is the use of EUS essential to determine whether ESD is indicated? } & 1. Rectal EUS only & 42.9 \\
\hline & 2. Both colon and rectal EUS & 57.1 \\
\hline \multirow{5}{*}{$\begin{array}{l}\text { Practically, which method do you most commonly use to determine } \\
\text { whether you try ESD or not? }\end{array}$} & 1. Gross morphology & 60.0 \\
\hline & 2. Magnifying colonoscopy & 0 \\
\hline & 3. NBI & 0 \\
\hline & 4. EUS & 0 \\
\hline & 5. Nonlifting sign & 40.0 \\
\hline \multirow{5}{*}{$\begin{array}{l}\text { Ideally, what is the most accurate method for evaluating the depth of } \\
\text { invasion, in your opinion? }\end{array}$} & 1. Gross morphology & 23.1 \\
\hline & 2. Magnifying colonoscopy & 30.8 \\
\hline & 3. NBI & 15.4 \\
\hline & 4. EUS & 30.8 \\
\hline & 5. Nonlifting sign & 0 \\
\hline
\end{tabular}

ESD, endoscopic submucosal dissection; HD, high definition; $\mathrm{NBI}$, narrow band imaging.

neoplasms. In practice, endoscopists most commonly use gross morphology patterns such as size, shape, and surface to determine the treatment modality for colorectal neoplasms. Korean endoscopists believe that magnifying endoscopy and EUS are the most accurate methods for evaluating the depth of tumor invasion; however, they do not believe that either magnifying endoscopy or EUS are practical, usable options.

\section{DISCUSSION}

With the development of various endoscopic tools, devices, increased experience, and growing expertise in ESD, colorectal ESD is now routinely performed in Korea. Originally used for gastric tumors and not for colorectal tumors, there are, however, important differences between superficial gastric tumors and superficial colorectal tumors. These include gastric tumors usually being carcinomatous, whereas colorectal tumors are mostly benign lesions. ${ }^{6,15}$ The rate of 
local recurrence after piecemeal resection of intramucosal tumors of the colorectum has increased; ${ }^{10,16}$ however, even in such cases, residual or recurrent tumors can be treated with repeated endoscopic resection or surgery. In this regard, en bloc resection of colorectal tumors is less absolute than that of gastric tumors. At the same time, the advances in magnifying endoscopy with dye-spraying and image-enhancement endoscopy have enabled the preprocedural assessment of histology and invasion depth of tumors with high accuracy. ${ }^{17-19}$

In this study, we surveyed the criteria of endoscopists for indicating colorectal ESD in their practice. From the survey, lesions such as LST-NG or tumors with type V-I pit pattern or type III-a NBI pattern, or tumors with a depressed area or shallow submucosa-invasive cancer cases were favored for colorectal ESD. These lesions have a significantly higher possibility of submucosal invasion and require en bloc resection for an accurate pathological evaluation. Other types of lesions chosen for colorectal ESD include tumors with partial submucosal fibrosis, tumors with partially nonlifting shallow submucosal invasion, tumors that are sporadically localized in the background of chronic inflammation, and cases of local residual early cancer after endoscopic resection. These types of lesions are included in the indication for ESD because the lesions are technically difficult to treat with conventional EMR. The selection criteria for colorectal ESD from our survey are almost the same as the indications for colorectal ESD in Japan. ${ }^{11}$ In addition, more benign-looking tumors tended to be included in clinical practice for colorectal ESD, as LST-G nodular mixed type, tumors with types III and IV pit pattern, and serrated tumors with type II NBI pattern are mostly benign lesions confined to the mucosa. In practice, the indications by Korean endoscopists for colorectal ESD are broader than those in the recent guidelines. ${ }^{11,20}$

Comparisons of outcomes for colorectal ESD versus EMR for large colorectal tumors have been reported in several clinical studies. ${ }^{10,21,22}$ For large colorectal tumors, ESD had higher en bloc resection rates and lower recurrence rates than EMR, but had higher complication rates and required a longer procedure time. Although the local recurrence rates of the EMR group were higher than those of the ESD group, $89.8 \%$ of recurrent cases were successfully treated with additional EMR. Only $10.2 \%$ of recurrent cases required additional surgical resection. ${ }^{10,22}$ Therefore, EPMR for large colorectal tumors is an acceptable treatment method. Significantly, when preprocedural diagnosis is performed precisely, recurrent lesions will usually be adenomas and additional endoscopic resection will be successful without surgical treatment.

Before performing colorectal ESD or EMR, diagnosis based on image-enhanced endoscopy and magnifying endoscopy allows for the distinction of a carcinoma from an adenoma and for estimating the invasion depth of the tumor. ${ }^{23,24}$ The diagnostic accuracy rate of discrimination between adenoma and carcinoma was $70 \%$ to $90 \%$ for pit pattern diagnosis with magnifying observation, and a similar rate was obtained by using image-enhancement endoscopy such as NBI. ${ }^{17-19}$ There are two subtypes of LST, namely LST-G and LST-NG. The rate of submucosal invasion in LST-NG was significantly higher than that of LST-G. In LST-G nodular mixed type, submucosal invasion may exist in a large nodule or an area of a type V-I pit pattern. ${ }^{25}$ Importantly, EPMR without breaking the carcinomatous portion into fragments should be applied. For LST-NG cases, the lesion should be removed en bloc with ESD because there is a higher potential for invasion and fibrosis, and the specimen obtained from the complete en bloc excision can be pathologically evaluated in detail. ${ }^{20,25-27}$

From our survey, endoscopists tend to conduct colorectal ESD for apparent adenomatous LST lesions in their practice. Although en block resection such as ESD is desirable if applicable, colorectal ESD is technically difficult, time consuming, and has a high risk of complications such as perforation. The objective of endoscopic treatment for adenoma is elimination of the lesion; therefore, EPMR is a good alternative treatment method for eliminating an obvious adenoma. Through precise preprocedural diagnosis, prearranged EPMR with minimal fractions is an appropriate treatment method for adenomatous LST lesions. Endoscopists should not perform superfluous ESD merely to improve their own ESD skills or for other reasons of self-interest, as this could unnecessarily place the patient at a risk of complications. To establish a standard indication for colorectal ESD, it is important to balance the need for completeness of treatment versus patient safety and simplified treatment.

\section{ACKNOWLEDGEMENTS}

The authors wish to thank the members of the Korean Society of Gastrointestinal Endoscopy/ESD group for their participation.

\section{REFERENCES}

1. Niimi K, Fujishiro M, Kodashima S, et al. Long-term outcomes of endoscopic submucosal dissection for colorectal epithelial neoplasms. Endoscopy 2010;42:723-729. 
2. Repici A, Hassan C, De Paula Pessoa D, et al. Efficacy and safety of endoscopic submucosal dissection for colorectal neoplasia: a systematic review. Endoscopy 2012;44:137-150.

3. Saito Y, Uraoka T, Yamaguchi Y, et al. A prospective, multicenter study of 1111 colorectal endoscopic submucosal dissections (with video). Gastrointest Endosc 2010;72:1217-1225.

4. Lee EJ, Lee JB, Lee SH, Youk EG. Endoscopic treatment of large colorectal tumors: comparison of endoscopic mucosal resection, endoscopic mucosal resection-precutting, and endoscopic submucosal dissection. Surg Endosc 2012;26:2220-2230.

5. Saito Y, Uraoka T, Matsuda T, et al. Endoscopic treatment of large superficial colorectal tumors: a case series of 200 endoscopic submucosal dissections (with video). Gastrointest Endosc 2007;66:966-973.

6. Tanaka S, Oka S, Kaneko I, et al. Endoscopic submucosal dissection for colorectal neoplasia: possibility of standardization. Gastrointest Endosc 2007;66:100-107.

7. Chang DK. Current status of colorectal endoscopic submucosal dissection in Korea. Clin Endosc 2012;45:288-289.

8. Kiriyama S, Saito Y, Yamamoto S, et al. Comparison of endoscopic submucosal dissection with laparoscopic-assisted colorectal surgery for early-stage colorectal cancer: a retrospective analysis. Endoscopy 2012;44:1024-1030.

9. Park SU, Min YW, Shin JU, et al. Endoscopic submucosal dissection or transanal endoscopic microsurgery for nonpolypoid rectal high grade dysplasia and submucosa-invading rectal cancer. Endoscopy 2012;44:1031-1036.

10. Saito Y, Fukuzawa M, Matsuda T, et al. Clinical outcome of endoscopic submucosal dissection versus endoscopic mucosal resection of large colorectal tumors as determined by curative resection. Surg Endosc 2010;24:343-352.

11. Tanaka S, Kashida H, Saito Y, et al. JGES guidelines for colorectal endoscopic submucosal dissection/endoscopic mucosal resection. Dig Endosc 2015;27:417-434.

12. Lee EJ, Lee JB, Lee SH, et al. Endoscopic submucosal dissection for colorectal tumors--1,000 colorectal ESD cases: one specialized institute's experiences. Surg Endosc 2013;27:31-39.

13. Kudo S, Rubio CA, Teixeira CR, Kashida H, Kogure E. Pit pattern in colorectal neoplasia: endoscopic magnifying view. Endoscopy 2001;33:367-373.

14. Tanaka S, Sano Y. Aim to unify the narrow band imaging (NBI) magnifying classification for colorectal tumors: current status in Japan from a summary of the consensus symposium in the 79th Annual Meeting of the Japan Gastroenterological Endoscopy Society. Dig Endosc 2011;23 Suppl 1:131-139.

15. Gotoda T, Yamamoto H, Soetikno RM. Endoscopic submucosal dissection of early gastric cancer. J Gastroenterol 2006;41:929942.
16. Puli SR, Kakugawa Y, Saito Y, Antillon D, Gotoda T, Antillon MR. Successful complete cure en-bloc resection of large nonpedunculated colonic polyps by endoscopic submucosal dissection: a meta-analysis and systematic review. Ann Surg Oncol 2009;16:2147-2151.

17. Kaltenbach T, Sano Y, Friedland S, Soetikno R; American Gastroenterological Association. American Gastroenterological Association (AGA) Institute technology assessment on imageenhanced endoscopy. Gastroenterology 2008;134:327-340.

18. Tanaka S, Kaltenbach T, Chayama K, Soetikno R. High-magnification colonoscopy (with videos). Gastrointest Endosc 2006;64:604-613.

19. Ikematsu H, Saito Y, Tanaka S, et al. The impact of narrow band imaging for colon polyp detection: a multicenter randomized controlled trial by tandem colonoscopy. J Gastroenterol 2012;47:1099-1107.

20. Tanaka S, Oka S, Chayama K. Colorectal endoscopic submucosal dissection: present status and future perspective, including its differentiation from endoscopic mucosal resection. J Gastroenterol 2008;43:641-651.

21. Iizuka H, Okamura S, Onozato Y, Ishihara H, Kakizaki S, Mori M. Endoscopic submucosal dissection for colorectal tumors. Gastroenterol Clin Biol 2009;33:1004-1011.

22. Tajika M, Niwa Y, Bhatia V, et al. Comparison of endoscopic submucosal dissection and endoscopic mucosal resection for large colorectal tumors. Eur J Gastroenterol Hepatol 2011;23:10421049.

23. Kanao H, Tanaka S, Oka S, Hirata M, Yoshida S, Chayama K. Narrow-band imaging magnification predicts the histology and invasion depth of colorectal tumors. Gastrointest Endosc 2009;69(3 Pt 2):631-636.

24. Oba S, Tanaka S, Oka S, et al. Characterization of colorectal tumors using narrow-band imaging magnification: combined diagnosis with both pit pattern and microvessel features. Scand J Gastroenterol 2010;45:1084-1092.

25. Uraoka T, Saito Y, Matsuda T, et al. Endoscopic indications for endoscopic mucosal resection of laterally spreading tumours in the colorectum. Gut 2006;55:1592-1597.

26. Oka S, Tanaka S, Kanao H, Oba S, Chayama K. Therapeutic strategy for colorectal laterally spreading tumor. Dig Endosc 2009;21 Suppl 1:S43-S46.

27. Kang SG, Lee SH, Chung SK, et al. Endoscopic treatment strategy for large laterally spreading tumor: endoscopic piecemeal mucosal resection or endoscopic submucosal dissection. Intest Res 2011;9:211-216. 